\title{
Tratamiento de recesiones múltiples localizadas: a propósito de un caso
}

\author{
ROCHA ABRAMOVICH A* \\ FERRUS CRUZ J**
}

Rocha Abramovich A, Ferrus Cruz J. Tratamiento de recesiones múltiples localizadas: a propósito de un caso. Av Periodon Implantol. 2007; 19, 1: 19-28.

\begin{abstract}
RESUIMEN
Las recesiones gingivales constituyen una preocupación tanto estética como funcional para el paciente odontológico. En el caso que se presenta se emplean tres distintas técnicas con injerto de tejido conectivo para tratar cinco recesiones gingivales que afectaban a cinco dientes en los tres sextantes del maxilar superior en una paciente mujer de 29 años. Todas las recesiones gingivales clase II de Miller se trataron con éxito. Se consiguió un recubrimiento total de las raíces.
\end{abstract}

\section{PALABRAS CLAVE}

Recesiones gingivales. Injertos, Recubrimiento radicular.

Fecha de recepción: Julio 2005

Aceptado para publicación: Octubre 2006

\section{INTRODUCCIÓN}

Las recesiones gingivales, se definen como el desplazamiento apical del margen gingival con respecto al límite amelocementario de uno o varios dientes.

Se trata de un hallazgo común tanto en pacientes con enfermedad periodontal incipiente hasta avanzada, como en pacientes sin enfermedad periodontal y una buena higiene oral (1).

Por ello, profesionales corrigen quirúrgicamente las recesiones gingivales debido a causas estéticas, sensibilidad, caries o abrasión cervical sin estar necesariamente tratando un problema mucogingival. Si conside- ramos que estamos ante un problema mucogingival cuando existe inflamación y recesión gingival en áreas con poca o nula encía adherida (2).

\section{ETIOLOGÍA}

Con respecto a las causas que producen recesión localizada debemos diferenciar entre factores predisponentes y factores desencadenantes. Entre los factores predisponentes se encuentran las dehiscencias en la tabla vestibular, que son un prerrequisito para que se produzca una recesión, pero no producirán necesariamente una recesión por existir. Un biotipo gingival fino, poca cantidad de encía queratinizada en altura, o in- 
serción alta de los frenillos, son otros factores que influyen y pueden predisponer hacia una futura recesión, pero no son causa directa de ellas $(3,4)$.

Sin embargo, el acúmulo de placa, o un trauma mecánico como el cepillado, sí pueden ser factores desencadenantes de recesiones gingivales $(2,5,1,6)$. No existe ninguna evidencia de que el trauma oclusal, ya sea primario o secundario, juegue papel alguno a la hora de producir este tipo de lesiones.

Existe evidencia científica para sugerir que la causa principal de las recesiones localizadas en pacientes jóvenes es el cepillado traumático, mientras que en adultos la enfermedad periodontal puede ser la causa principal (5).

\section{CLASIFICACIONES}

Se han descrito diferentes clasificaciones de las recesiones gingivales a lo largo de la historia $(7,8)$. Entre las más utilizadas se encuentra la de Miller, descrita en 1985, y en el presente artículo seguiremos dicha clasificación, ya que es la única que sirve además para establecer un pronóstico a nuestro tratamiento con injertos.

- Clase I: recesión del tejido marginal que no excede la línea mucogingival, sin afectación del periodonto interproximal. Se puede conseguir un recubrimiento radicular del $100 \%$.

- Clase II: recesión del tejido marginal que excede la línea mucogingival, sin afectación del periodonto interproximal. Se puede conseguir un recubrimiento radicular del $100 \%$.

- Clase III: recesión del tejido marginal que alcanza o sobrepasa la línea mucogingival, existe afectación del hueso interproximal o de la papila, o una malposición del diente que imposibilita conseguir un recubrimiento radicular del $100 \%$. Se puede esperar un recubrimiento parcial de la lesión.

- Clase IV: recesión del tejido marginal que alcanza o sobrepasa la línea mucogingival, existe una afectación del hueso interproximal, de la papila o una malposición dentaria tan severas, que no es aconsejable intentar el recubrimiento radicular.

En el siguiente caso clínico se describen tres técnicas distintas en las que se emplea injerto de tejido conectivo para tratar recesiones gingivales de clase II.

\section{INDICACIONES PARA ELTRATAMIENTO MEDIANTE CIRUGÍA MUCOGINGIVAL}

Debemos diferenciar dos situaciones distintas: cuando existe una recesión gingival y queremos cubrirla por motivos estéticos o de sensibilidad, y otra diferente cuando exista poca o nada de encía queratinizada (asociada o no a una recesión). Ambas situaciones se tratan mediante cirugía mucogingival.

Hoy día se sabe que la cantidad de encía queratinizada no es un factor esencial para el buen mantenimiento de la integridad del periodonto $(9,3,10,4)$. Sin embargo hablamos de inadecuada cantidad de encía queratinizada según la situación del diente en concreto.

Existen situaciones en las que estará indicado este tipo de tratamientos no sólo por motivos estéticos, sino también por motivos profilácticos para evitar una futura recesión, o que la presente no progrese. Entre las indicaciones principales estarán restauraciones subgingivales, movimientos ortodóncicos o una inadecuada higiene oral a ese nivel por molestias referidas por el paciente debidas a la ausencia de tejido queratinizado.

En cuanto al tratamiento ortodóncico, si el diente es movido exclusivamente dentro del hueso alveolar en bloque, la recesión gingival no se produce (3). Si se va a realizar un movimiento de versión hacia vestibular y se sospecha que parte de la raíz quedará fuera del proceso alveolar se asegurará un mínimo de encía insertada, tanto en altura como en grosor, para evitar la recesión.

La elección de la técnica a emplear en el tratamiento de las recesiones depende de cuatro puntos: éxito, reproducibilidad, ausencia de morbilidad y coste. Básicamente, cuanto más sencilla es la técnica más reproducible será. Los injertos de tejido conectivo se consideran una buena alternativa para el tratamiento de recesiones gingivales (11).

\section{DESCRIPCIÓN DEL CASO}

Paciente mujer, de 29 años, con un buen estado de salud general, acudió al Master de Periodoncia de la U.C.M (Universidad Complutense de Madrid). Debido a que presentaba recesiones gingivales múltiples en los tres sextantes del maxilar superior. Había recibido tratamiento ortodóncico hace unos años.

Al paciente le preocupaba sobre todo la estética de sus encías, pero también refería problemas de sensi- 
bilidad dentinaria. Las recesiones que presentaba eran clases II de Miller (Figura 1).

Su nivel de higiene oral era bueno, pero su técnica fue modificada en favor de un cepillado más suave mediante técnica de Stillman. Estaba motivada para recibir el tratamiento.

En una primera cita, se le realizó la historia clínica y una profilaxis en toda la boca, se citó al paciente una semana después.

En el primer sextante se decidió colocar un injerto de tejido conectivo empleando la técnica de Langer (12).

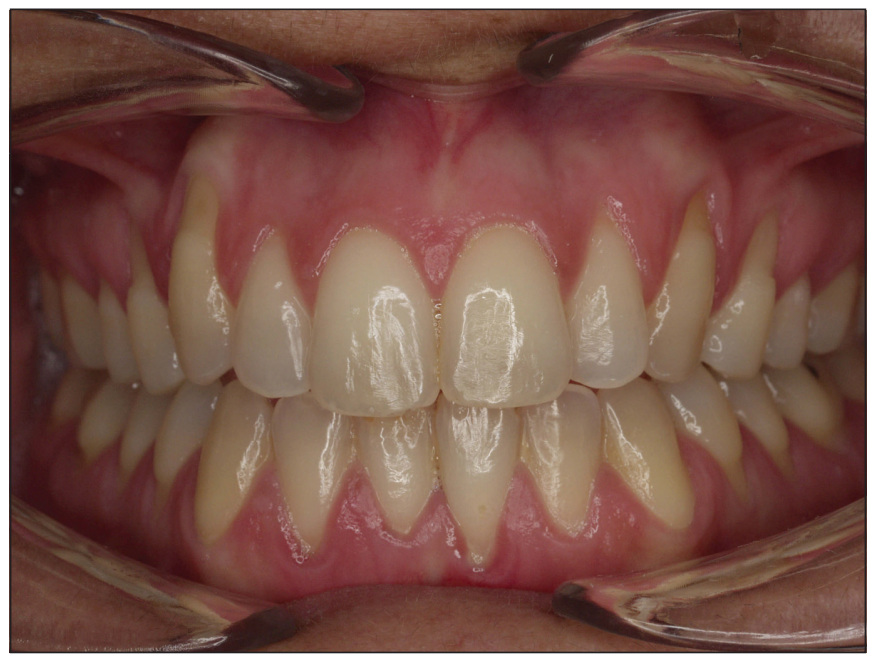

Fig. 1: Situación inicial del paciente. Obsérvese la magnitud de las recesiones y el escaso grosor del periodonto.

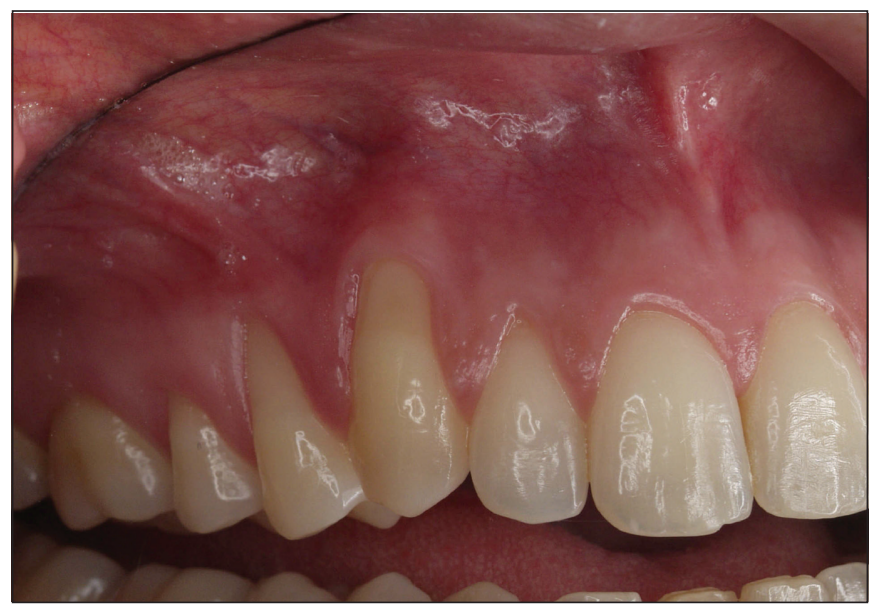

Fig. 2: situación inicial del ler Cuadrante.
Una vez administrado el anestésico local (lidocaína 2\% $1: 100.000$ ), se realizó una incisión horizontal a nivel del límite amelocementario respetando las papilas junto con una incisión liberadora en distal, en la línea ángulo del 15. Se separó colgajo a espesor parcial, hasta sobrepasar la línea mucogingival unos milímetros. A nivel del 13 se evitó realizar incisión liberadora debido al compromiso estético, en su lugar no se separó la papila y se creó un sobre de espesor parcial por la parte mesial. (Figura 3).

Se tomó el injerto en el mismo lado para circunscribir el área cruenta al lado derecho, y mejorar el confort del paciente durante el postoperatorio. Se realizó una incisión por palatino del 16 al 13 con una incisión liberadora en mesial para acceder al injerto de tejido conectivo mediante la técnica de trampilla (Figuras 4 y 5), se obtuvo un injerto de conectivo de $25 \mathrm{~mm}$ de longitud y entre 6 y $9 \mathrm{~mm}$ de ancho suficiente para cubrir las recesiones en 15, 14 y 13 (Figura 6). Se suturó la zona donante con sutura Supramid $囚$ de 4 ceros (Figura 7 ).

El injerto fue suturado en la zona receptora mediante suturas reabsorbibles, en las zonas que iban a ser cubiertas por el colgajo, ancladas al periostio y conectivo remanente no desinsertado en la reflexión del colgajo (Figura 8). Para alcanzar un mayor recubrimiento del injerto con el colgajo, se realizaron varias incisiones en el fondo del vestíbulo. Una vez liberado, se suturó a nivel de las papilas (Figura 9). Se prescribieron analgésicos y antiinflamatorios durante 4 días (Ibupro-

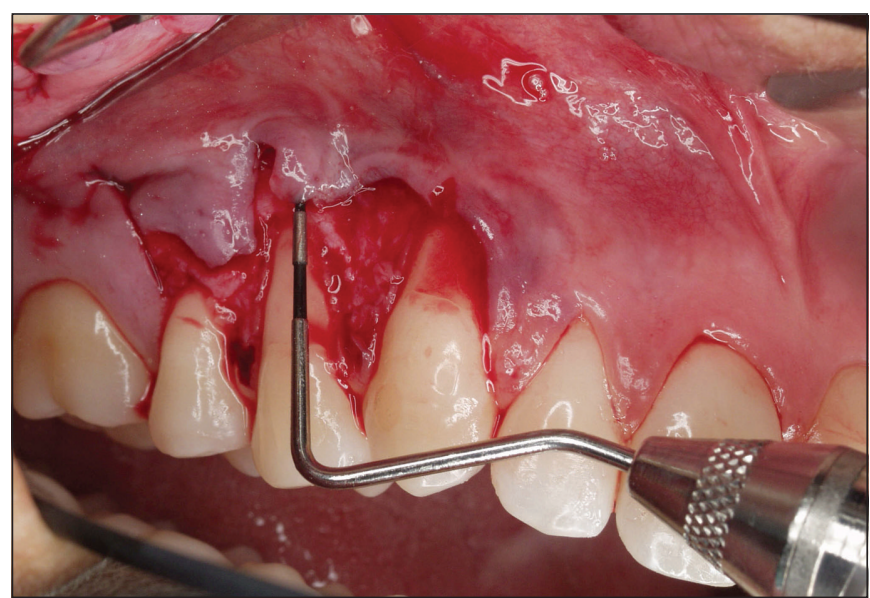

Fig. 3: Se despega un colgajo a espesor parcial con incisiones iniciales intrasurculares y una liberadora en distal. También se despega en sobre por debajo del 12 sin despegar la papila del 13-12. 


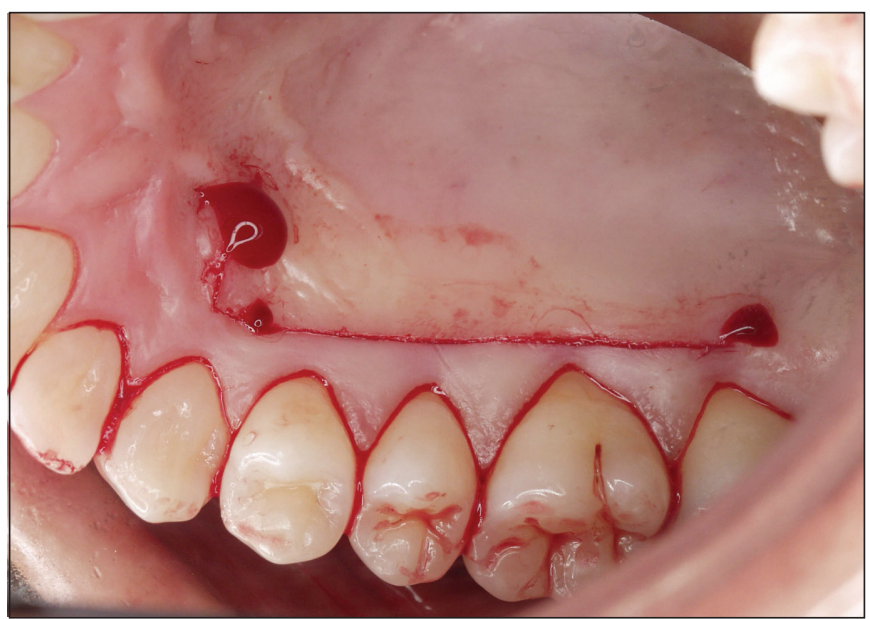

Fig. 4: Amplia incisión en la zona donante para adquirir un injerto de dimensiones adecuadas.

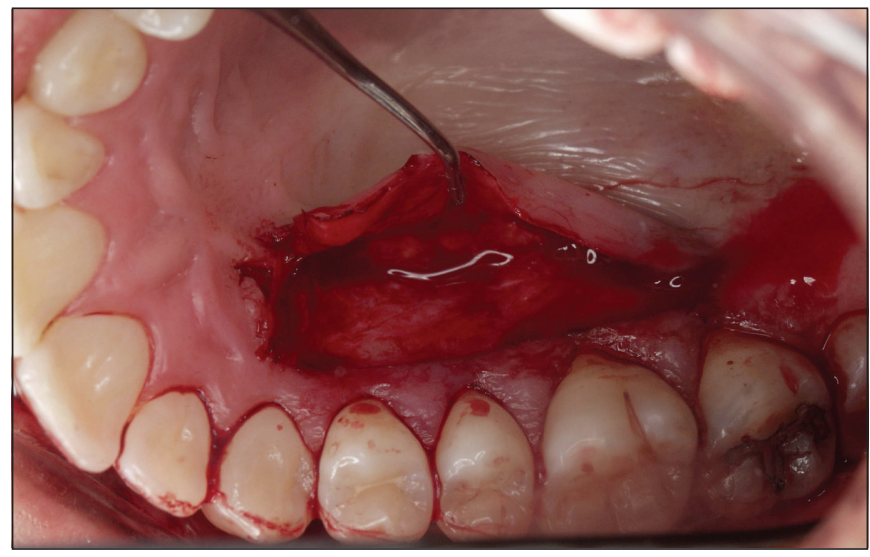

Fig. 5: Despegamiento del paladar a dos espesores .

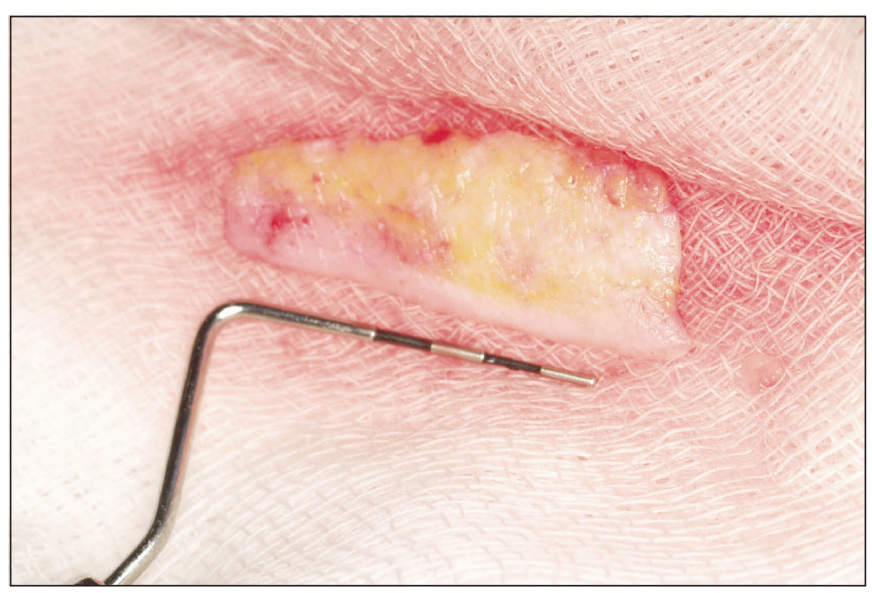

Fig. 6: Obtención del injerto de más de $20 \times 8 \mathrm{~mm}$.

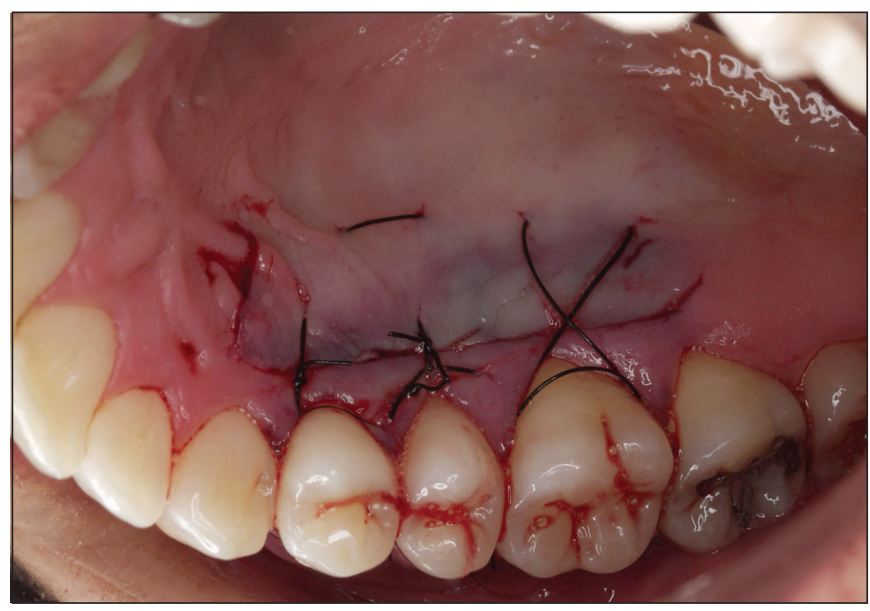

Fig. 7: Cierre de la zona donante dejando en nudo por vestibular.

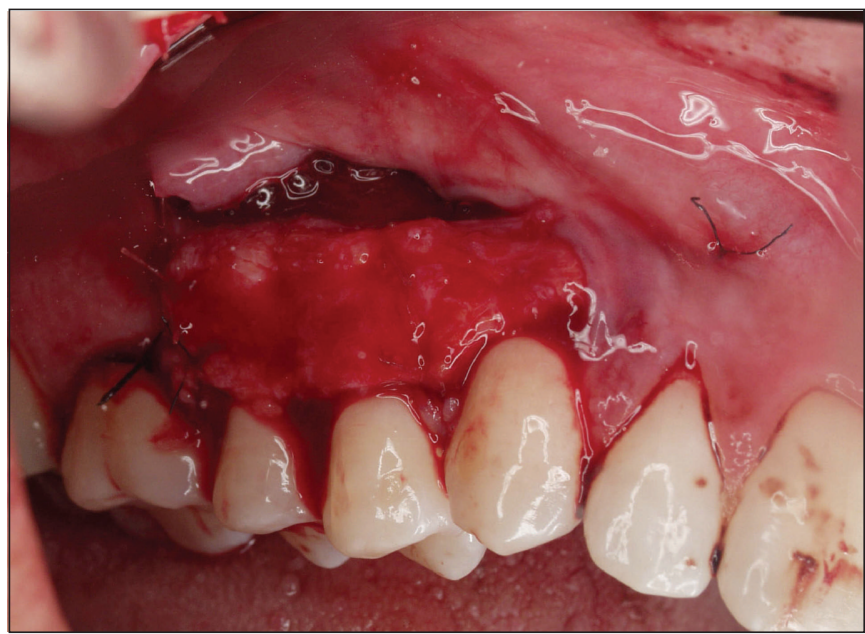

Fig. 8: El injerto obtenido es suficiente para cubrir las múltiples recesiones.

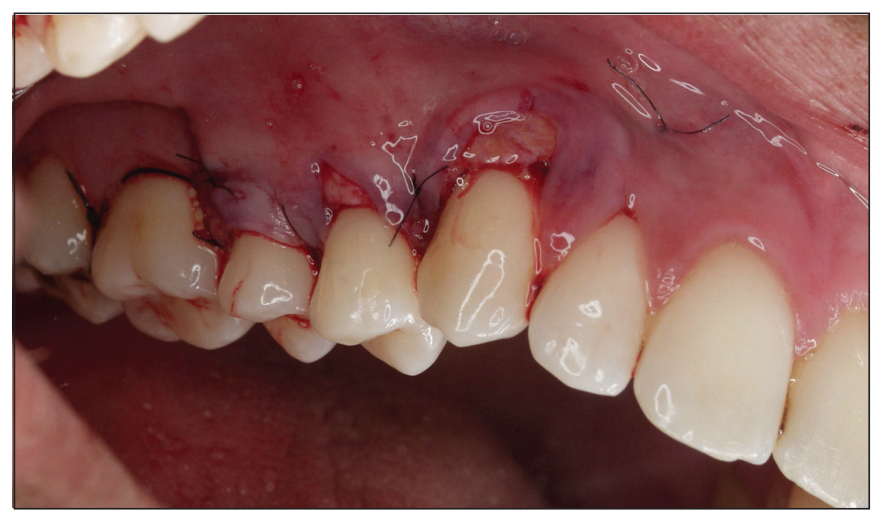

Fig. 9: Injerto suturado en su posición. 


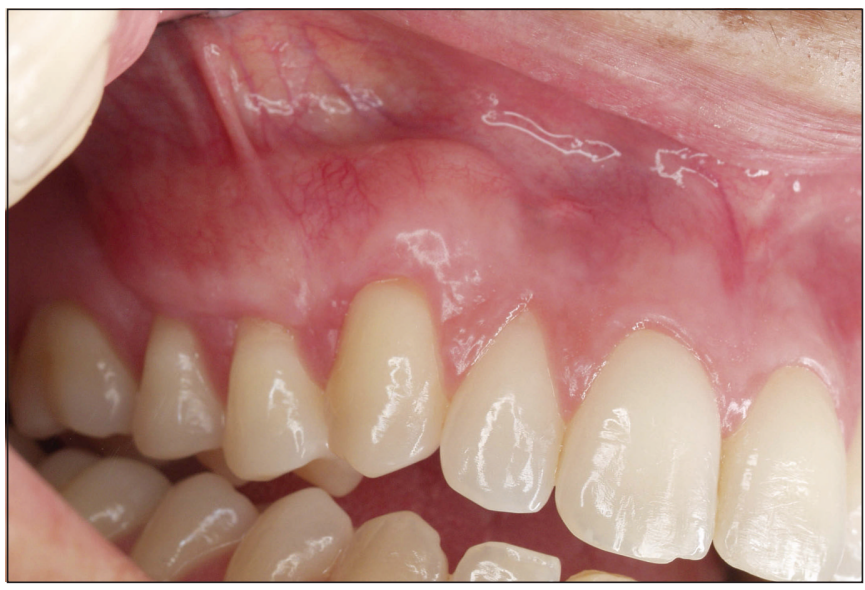

Fig. 10: Imagen a las 8 semanas de la intervención.

feno 600 cada 8 horas y paracetamol $1 \mathrm{~g}$ cada $12 \mathrm{~h}$ ). Se recomendó no cepillar esa zona durante 2 semanas y aplicar Clorhexidina 0,12\% en Spray sobre la zona receptora del injerto 3 veces/día. No se utilizó ningún tipo de cemento quirúrgico. El paciente sufrió molestias moderadas durante los tres primeros días, a pesar de la medicación, a nivel del paladar. Las suturas a nivel del paladar se retiraron a la semana y las de la zona receptora a las dos semanas.

El paciente acudió dos semanas después de la primera cirugía para tratar el tercer sextante. En este sextante se decidió realizar en un principio una técnica de reposición coronal descrita por G. Zucchelli y M. De Sanctis (13). Sin embargo al apreciarse que la mucosa era demasiado fina se prefirió adjuntar un injerto de tejido conectivo. Se administró el anestésico local, se realizaron unas incisiones oblicuas submarginales en las zonas interdentales junto con una incisión intrasurcular en la zona de la recesión (Figuras 11 y 12). Las papilas se denudaron para dejar el tejido conectivo subyacente expuesto para así suturar a ese nivel nuestro colgajo desplazándolo coronalmente.

Se tomó un injerto de $15 \mathrm{~mm}$ de tejido conectivo del paladar del mismo lado, en este caso se hizo una sola incisión horizontal en la zona de premolares y primer molar para acceder a la toma del injerto. (Figura 13).

Se suturó la zona donante con Supramid $₫$ de cuatro ceros, el injerto se colocó con sutura reabsorbible SSA $®$ de seis ceros y el colgajo se reposicionó coronalmente con Supramid $囚$ de seis ceros y puntos dento-suspendi-

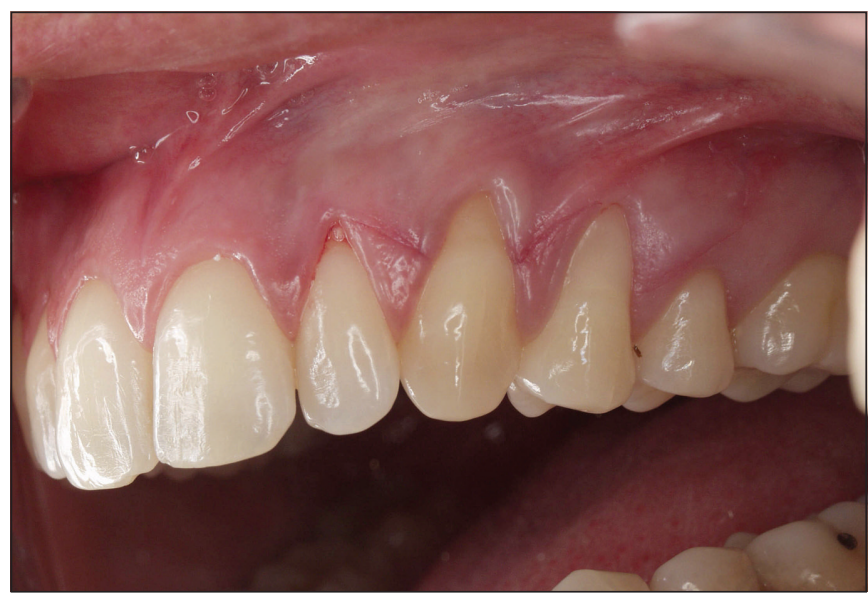

Fig. 11: Situación inicial previa a la intervención. Se marcan las incisiones para realizar un colgajo de avance coronal según Zuchelli y DeSanctis 2004. Sin embargo se utilizó un injerto para garantizar el recubrimiento de las raíces.

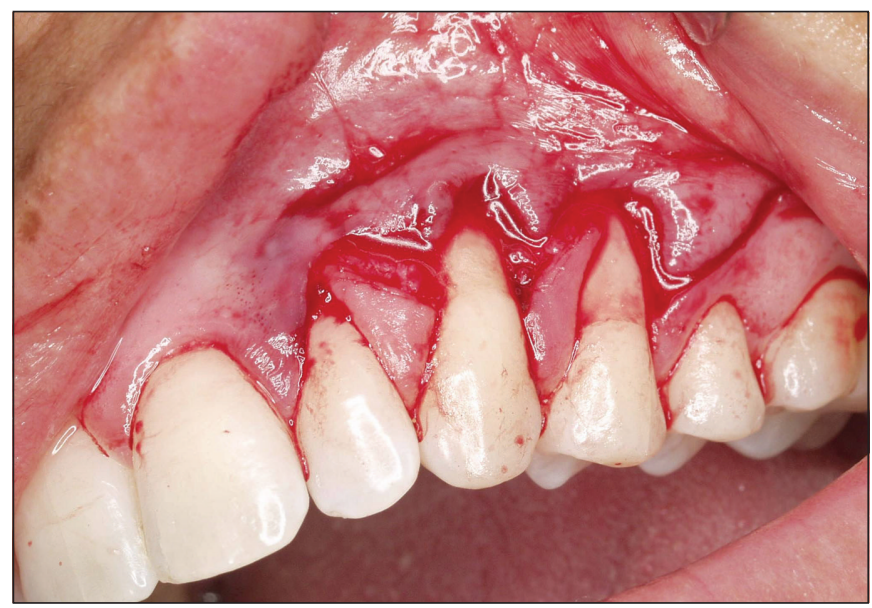

Fig. 12: Despegamiento a espesor parcial.

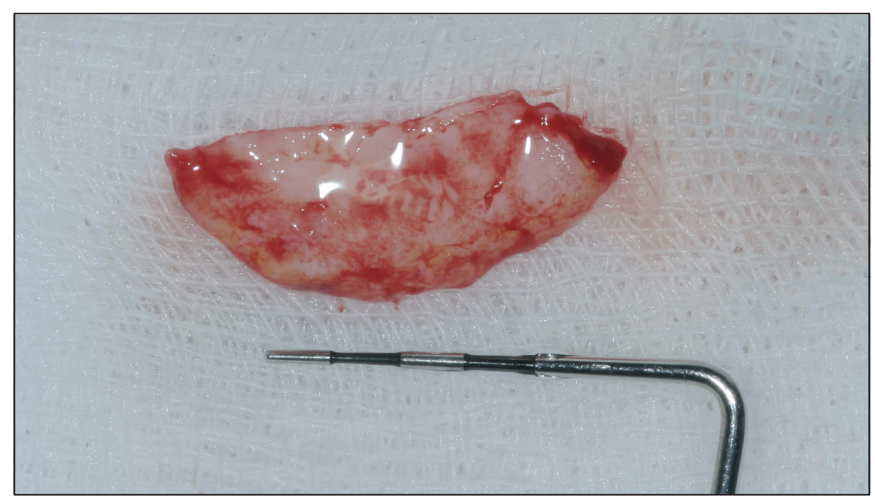

Fig. 13: Obtención del injerto del paladar homo-lateral. 
dos (Figuras 14 y 15). Se prescribieron analgésicos y antiinflamatorios durante 4 días (Ibuprofeno $600 \mathrm{cada}$ $8 \mathrm{~h}$ y paracetamol $\mathrm{l} \mathrm{g}$ cada $12 \mathrm{~h}$ ). El paciente, esta vez, no refirió molestias durante el postoperatorio.

Tras las dos intervenciones, el paciente presentaba una recesión remanente de $2 \mathrm{~mm}$ a nivel de 22 (Figura 17). Se decidió realizar una técnica de sobre descrita por P. Raetzke (14). Se administró anestésico local y se preparó el sobre con una incisión a espesor parcial en la zona de la recesión sin liberadoras y sin reflejar el colgajo. Se utilizó un micro bisturí daba la dimensión de la zona receptora y la técnica a realizar. El injerto de tejido conectivo se tomó del paladar del lado izquierdo con una incisión horizontal del 26 al 27. Se suturó la

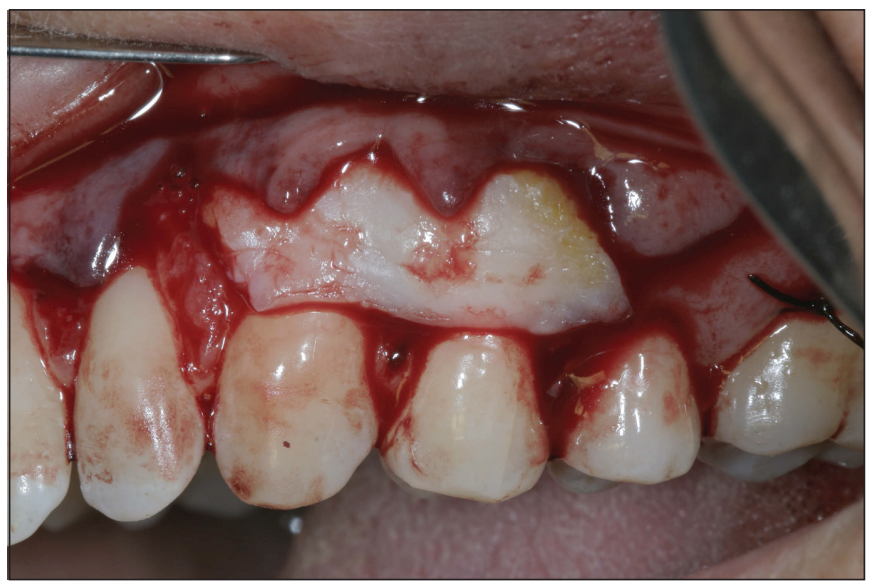

Fig. 14: Injerto en su posición.

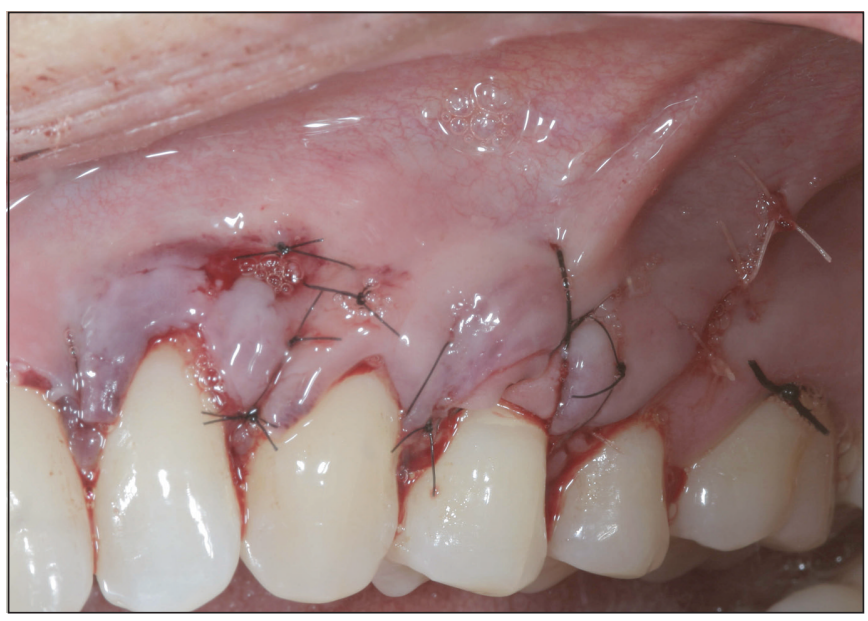

Fig. 15: Sutura.

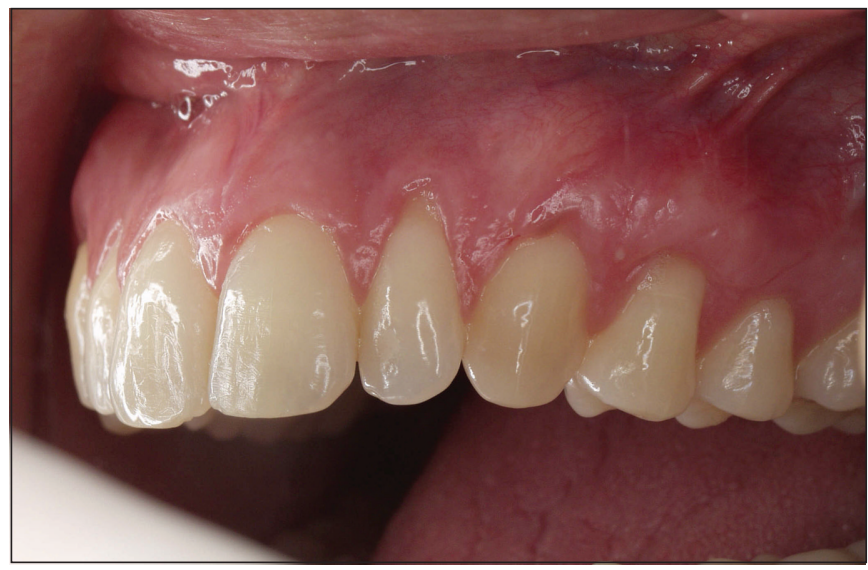

Fig. 16: Imagen a las 6 semanas de la intervención. Obsérvese la recesión de $1.5 \mathrm{~mm}$ que permanece e incluso ha aumentado tras la intervención a nivel del 22.

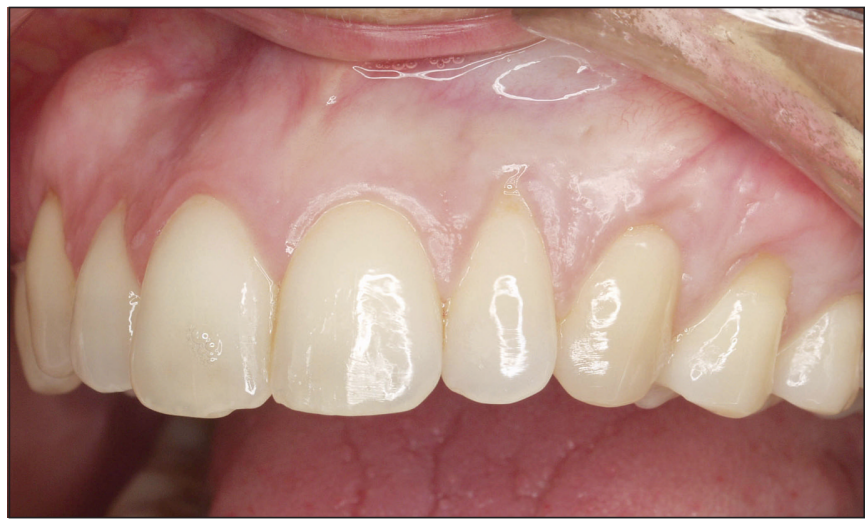

Fig.17: Situación previa a la intervención .

zona donante y el injerto con sutura Supramid $®$ de seis ceros (Figuras 18 y 19).

\section{DISCUSIÓN}

El tratamiento de las recesiones gingivales siempre representa un reto terapéutico. Diversas técnicas, incluyendo las técnicas que utilizan injertos de tejido conectivo, son parte del armamentarium que el profesional tiene hoy día para conseguir de forma predecible recubrimiento radicular y una buena estética.

En la literatura podemos observar unos buenos resultados obtenidos con diversas técnicas que emplean injertos de tejido conectivo $(5,15,12,14,16,17,13)$. 


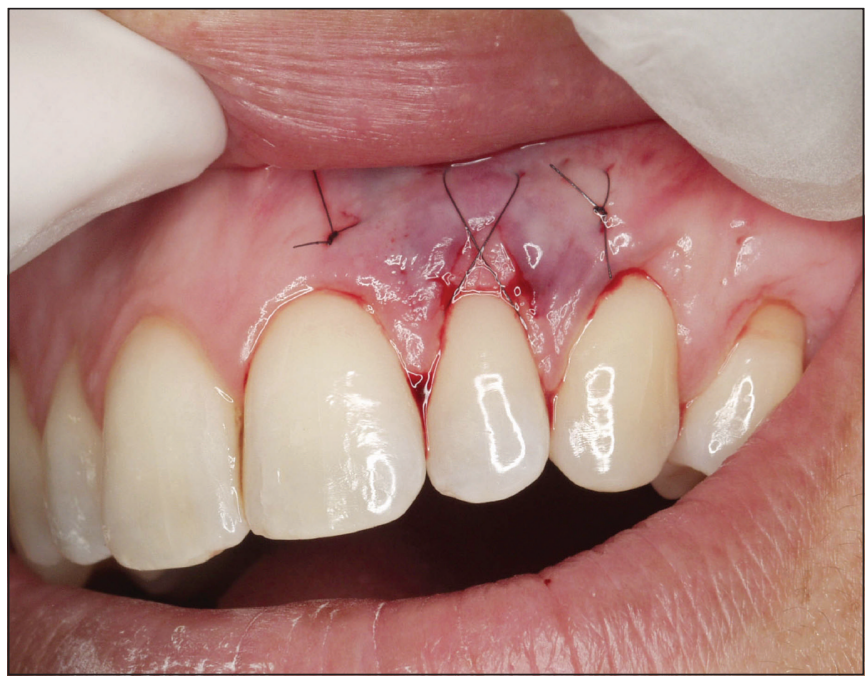

Fig. 18: Injerto en sobre colocado y fijado con 2 puntos colchoneros internos en los dos extremos del injerto y un punto tipo Holbrook.

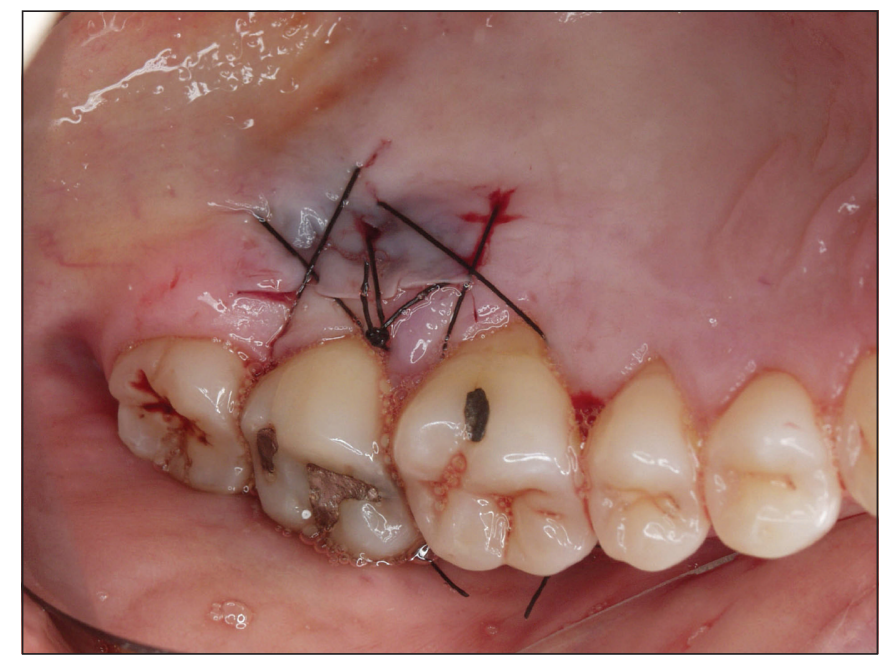

Fig.19: Sutura a nivel de la zona donante.

Bouchard y cols. (2001) en una revisión de la literatura nos muestran diversos estudios prospectivos donde se compara el uso de injertos de tejido conectivo sumergidos con diferentes técnicas de recubrimiento radicular (tabla 1). Para estos autores las técnicas que no utilizan membranas, incluyendo las que emplean injertos de tejido conectivo, son su preferencia a la hora de conseguir recubrimiento radicular con necesidades estéticas. Sin olvidar la posibilidad de conseguir nuevo hueso con el uso de membranas.

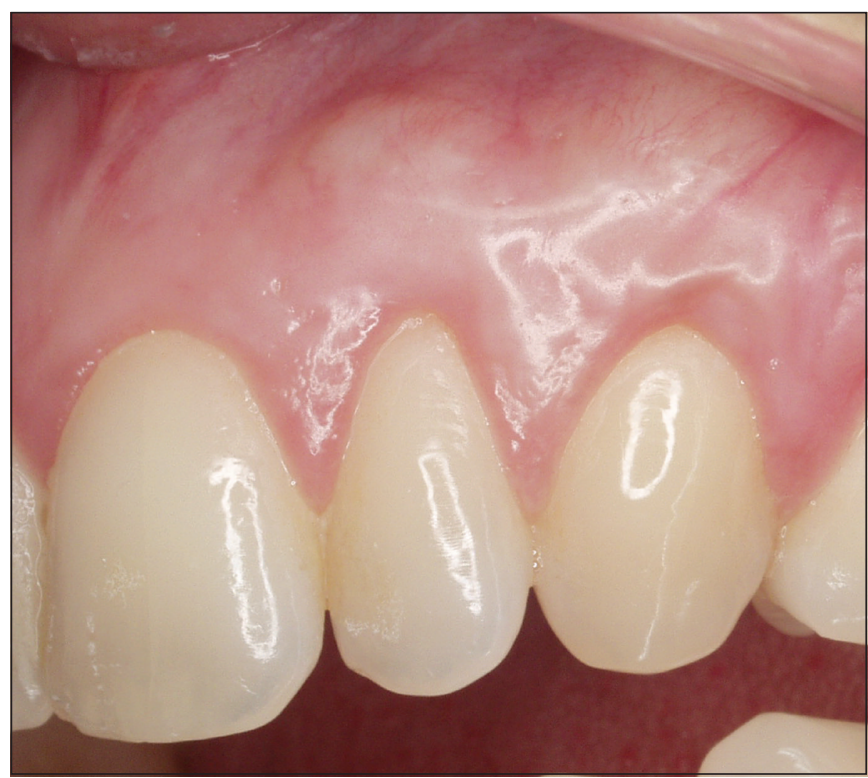

Fig. 20: Situación final 8 semanas después de la intervención.

Es de suma importancia una buena selección del paciente. La cantidad de recubrimiento radicular está directamente relacionado con la colaboración del paciente a corto y largo plazo (11). Pacientes que sean incapaces de mantener una higiene oral e instrucciones preoperatorias y postoperatorias adecuadas, no son buenos candidatos para este tipo de tratamiento.

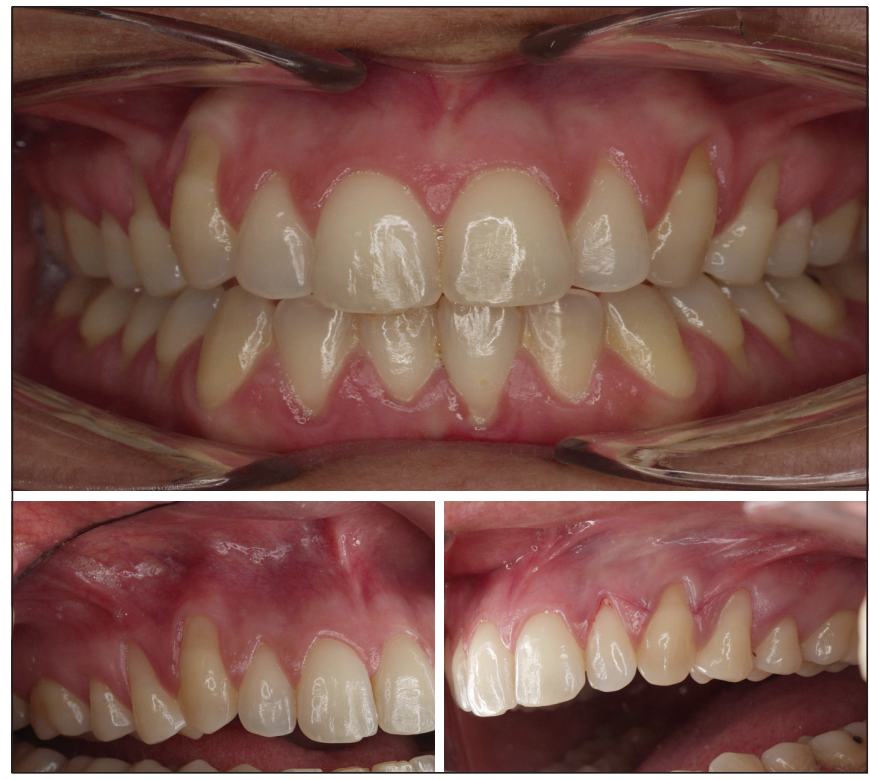

Fig. 21: Situación inicial del paciente. 


\section{TABLA 1.- ESTUDIOS PROSPECTIVOS COMPARANDO EL USO DE INJERTOS SUMERGIDOS DE TEJIDO CONECTIVO CON EL USO DE DIFERENTES PROCEDIMIENTOS DE RECUBRIMIENTO RADICULAR}

\begin{tabular}{|c|c|c|c|c|c|c|}
\hline Autor & Diseño del estudio & $\begin{array}{c}\text { Clase } \\
\text { del } \\
\text { defecto }\end{array}$ & $\begin{array}{c}\mathbf{N}^{\circ} \text { de } \\
\text { pacientes }\end{array}$ & $\begin{array}{l}\mathbf{N}^{\circ} \text { de } \\
\text { dientes }\end{array}$ & $\begin{array}{l}\% \text { medio } \\
\text { de } \\
\text { cobertura } \\
\text { radicular }\end{array}$ & $\begin{array}{l}\% \text { de dientes } \\
\text { con recubrim } \\
\text { radicular } \\
\text { total }\end{array}$ \\
\hline \multicolumn{7}{|c|}{ Injertos no sumergidos } \\
\hline Sbordone et al. & $\begin{array}{l}\text { Injerto de tejido conectivo subepitelial } \\
\text { Injerto libre de tejido conectivo }\end{array}$ & $\begin{array}{l}\text { I o II } \\
\text { I o II }\end{array}$ & $\begin{array}{l}12 \\
12\end{array}$ & $\begin{array}{l}12 \\
12\end{array}$ & $\begin{array}{c}52 \mathrm{~S} \\
11\end{array}$ & - \\
\hline Jahnke et al. & $\begin{array}{l}\text { Injerto de tejido conectivo (técnica } \\
\text { del sobre) } \\
\text { Injerto libre de tejido conectivo }\end{array}$ & $\begin{array}{l}\text { I y II } \\
\text { I y II }\end{array}$ & $\begin{array}{l}9 \text { con } \\
\text { defectos } \\
\text { pareados }\end{array}$ & $\begin{array}{l}9 \\
9\end{array}$ & $\begin{array}{c}80 \mathrm{~S} \\
43\end{array}$ & $\begin{array}{l}56 \\
11\end{array}$ \\
\hline Paolantonio et al. & $\begin{array}{l}\text { Injerto de tejido conectivo subepitelial } \\
\text { Injerto libre de tejido conectivo }\end{array}$ & $\begin{array}{l}\text { I y II } \\
\text { I y II }\end{array}$ & $\begin{array}{l}35 \\
35\end{array}$ & $\begin{array}{l}35 \\
35\end{array}$ & $\begin{array}{c}85 \mathrm{~S} \\
53\end{array}$ & \\
\hline \multicolumn{7}{|c|}{ Injertos pediculados } \\
\hline $\begin{array}{l}\text { Wennström } \\
\text { y Zucchelli }\end{array}$ & $\begin{array}{l}\text { Injerto de tejido conectivo subepitelial } \\
\text { Colgajo de reposición coronal }\end{array}$ & I & $\begin{array}{l}35 \\
32\end{array}$ & $\begin{array}{l}58 \\
45\end{array}$ & $\begin{array}{l}98 \mathrm{NS} \\
97\end{array}$ & $\begin{array}{l}88 \\
80\end{array}$ \\
\hline \multicolumn{7}{|c|}{ Procedimientos de RTG con membranas no reabsorbibles } \\
\hline Ricci et al. & $\begin{array}{l}\text { Injerto de tejido conectivo subepitelial } \\
\text { Gore-Tex + Colgajo de reposición } \\
\text { coronal }\end{array}$ & I y II & - & $\begin{array}{l}18 \\
18\end{array}$ & $\begin{array}{c}77 \text { NS } \\
81\end{array}$ & $\begin{array}{l}- \\
-\end{array}$ \\
\hline Jepsen et al. & $\begin{array}{l}\text { Injerto de tejido conectivo (técnica } \\
\text { del sobre) } \\
\text { Gore-Tex reforzado con titanio } \\
\text { + colgajo de reposición coronal }\end{array}$ & I y II & $\begin{array}{l}15 \mathrm{con} \\
\text { defectos } \\
\text { pareados }\end{array}$ & $\begin{array}{l}15 \\
15\end{array}$ & $\begin{array}{c}87 \text { NS } \\
87\end{array}$ & $\begin{array}{l}47 \\
47\end{array}$ \\
\hline \multicolumn{7}{|c|}{ Procedimientos de RTG con membranas reabsorbibles } \\
\hline Harris & $\begin{array}{l}\text { Injerto de tejido conectivo } \\
+ \text { colgajo de doble papila } \\
\text { Guidor + colgajo de reposición coronal }\end{array}$ & 1 & $\begin{array}{l}10 \\
10\end{array}$ & 10 & $\begin{array}{c}97 \text { NS } \\
75\end{array}$ & $\begin{array}{l}90 \\
60\end{array}$ \\
\hline Harris & $\begin{array}{l}\text { Injerto de tejido conectivo } \\
\text { subepitelial } \\
\text { Guidor + colgajo de reposición coronal }\end{array}$ & $\begin{array}{l}\text { I y II } \\
\text { I y II }\end{array}$ & $\begin{array}{l}12 \\
12\end{array}$ & $\begin{array}{l}19 \\
18\end{array}$ & $\begin{array}{l}95 \mathrm{NS} \\
92\end{array}$ & $\begin{array}{l}74 \\
72\end{array}$ \\
\hline Zucchelli et al. & $\begin{array}{l}\text { Injerto de tejido conectivo subepitelial } \\
\text { Guidor + colgajo de reposición coronal } \\
\text { Gore-Tex + colgajo de reposición } \\
\text { coronal }\end{array}$ & $\begin{array}{l}\text { I y II } \\
\text { I y II } \\
\text { I y II }\end{array}$ & $\begin{array}{l}18 \\
18 \\
18\end{array}$ & 12 & $\begin{array}{c}93,5 \mathrm{~S} \\
86 \mathrm{~S} \\
80,5 \mathrm{NS}\end{array}$ & $\begin{array}{l}66 \\
39 \\
28\end{array}$ \\
\hline Trombelli et al. & $\begin{array}{l}\text { Injerto de tejido conectivo subepitelial } \\
\text { Resolut + colgajo de reposición coronal }\end{array}$ & $\begin{array}{l}\text { I y II } \\
\text { I y II }\end{array}$ & $\begin{array}{l}12 \text { con } \\
\text { defectos } \\
\text { pareados }\end{array}$ & $\begin{array}{l}12 \\
12\end{array}$ & 6 & $\begin{array}{l}81 \mathrm{~S} \\
48\end{array}$ \\
\hline Borghetti et al. & $\begin{array}{l}\text { Injerto de tejido conectivo subepitelial } \\
\text { Guidor + colgajo de reposición coronal }\end{array}$ & $\begin{array}{l}\text { I } \\
\text { I }\end{array}$ & $\begin{array}{l}14 \text { con } \\
\text { defectos } \\
\text { pareados }\end{array}$ & $\begin{array}{l}14 \\
14\end{array}$ & 6 & $\begin{array}{c}76 \mathrm{SN} \\
70\end{array}$ \\
\hline Müller et al. & $\begin{array}{l}\text { Injerto de tejido conectivo (técnica } \\
\text { del sobre) } \\
\text { Guidor + colgajo de reposición coronal }\end{array}$ & $\begin{array}{l}\text { I y II } \\
\text { I y II }\end{array}$ & $\begin{array}{c}13 \\
9\end{array}$ & $\begin{array}{l}14 \\
14\end{array}$ & $\begin{array}{c}6 \\
45\end{array}$ & $80 \mathrm{~S}$ \\
\hline
\end{tabular}



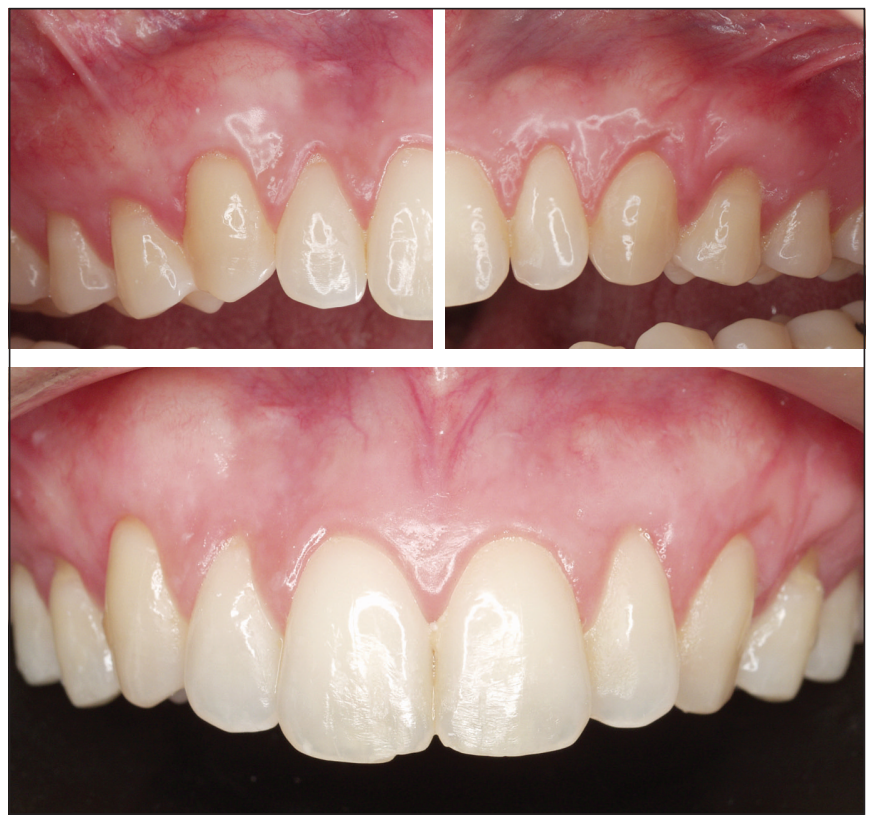

Fig. 22: Situación final.

En el caso clínico presentado, se decidió emplear tres distintas técnicas con injerto de tejido conectivo del paladar para las distintas recesiones clase II de Miller, debido a la gran predecibilidad que ofrecen este tipo de técnicas y a la buena colaboración y motivación de la paciente. Se obtuvieron unos buenos resultados con las tres técnicas.

\section{CONCLUSIÓN}

Este caso clínico demuestra, que utilizando técnicas de cirugía mucogingival que emplean injertos de tejido conectivo del paladar, es posible tratar varias recesiones de clase II de Miller. Obteniendo unos resultados satisfactorios en cuanto a las expectativas estéticas del paciente y reducción de la sensibilidad dentinaria.

\section{ABSTRACT}

Gingival recessions are of concern both esthetically and functionally for the dental patient. In the present case, three different procedures involving connective tissue graft were used to treat five gingival recessions on five teeth in the three maxillary sextants of a 29-year-old woman. All Miller class II recessions were successfully treated; complete root coverage was obtained at all treated sites.

\section{KEYWORDS}

Gingival recessions, grafts, root coverage.

\section{BIBLIOGRAFÍA}

1. Cangini F, Cornelini R, Andreana S. Simultaneus treatment of multiple, bilateral, deep bucal recession defects with bioabsorbable barrier membranes: $A$ case report. Quintessence Int 2003;34:15-8.

2. Camargo PM, Melnick PR, Kenney B.The use of free gingival grafts for aesthetic purposes. Periodontology 2000 2001;27:72-96.

3. Wennström JL. Lack of association between width of attached gingival and development of gingival recessions. A 5-year longitudinal study. J Clin Periodontol 1987;14:181-4.

4. Dorfman HS, Kennedy JE, Bird WC. Longitudinal evaluation of free autogenous gingival grafts. J Clin Periodontol 1982;53:349-52.

5. Lindhe J. Clinical Periodontology and Implant Dentistry. Blackwell, 2003.

6. Khocht A, Simon G, Person P, Denepitiya JL. Gingival recession in relation to history of hard toothbrush use. J Periodontol 1993; 64: 900-5.

7. Sullivan HC, Atkins JH. Free autogenous gingival grafts. III. Utilization of grafts in the treatment of gingival recession. Periodontics 1968;6:152-60.

8. Miller PD. A Classification of Marginal Tissue Recession. Int J Periodont Rest Dent 1985;2:9-13.

9. Lindhe J, Nyman S. Alterations of the position of the marginal soft tissue following periodontal surgery. J Clin Periodontol 1980;7:525-30.

10. Freedman AL, Green K, Salkin LM, Stein MD, Mellado JR. An 18-year longitudinal study of untreated mucogingival defects. J Periodontol 1999;70:1174-6.

11. Bouchard P, Malet J, Borghetti A. Decision-making in aesthetics: root coverage revisited. Periodontology 2000 2001;27:72-96.

12. Langer B, Laanger L. Subepithelial connective tissue graft technique for root coverage.J Periodontol 1985;56:7 15-20.

13. Zucchelli G,De Sanctis M. Treatment of multiple recessiontype defects in patients with esthetic demands. J Periodontol 2000;71:1506-14. 


\section{AVANCES}

14. Raetzke PB. Covering localized areas of root exposure employing the "envelope" technique. J Periodontol 1985;56:397-402.

15. Jahnke PV, Sandifer JB, Gher ME, Gray JL, Richardson AC. Thick free gingival and connective tissue autografts for root coverage. J Periodontol 1993;64:31522.

16. Bruno JF. Connective tissue graft technique assuring wide root coverage. Int J Periodont Rest Dent 1994;14: 127-37.
17. Paolantonio M. Treatment of gingival recessions by combined periodontal regenerative technique, guided tissue regeneration, and subpedicle connective tissue graft. A comparative clinical study- J Periodontol 2002; 73:53-62.

\section{CORRESPONDENCIA}

Alejandro Rocha Abramovich

Torquedama, $21,1^{\circ} 3$

28043 Madrid 